\title{
Retraction Note to: Epigallocatechin-3-gallate (EGCG) as a pro-osteogenic agent to enhance osteogenic differentiation of mesenchymal stem cells from human bone marrow: an in vitro study
}

\author{
Pan Jin ${ }^{1,4} \cdot$ Huayu $\mathrm{Wu}^{2} \cdot$ Guojie Xu ${ }^{1,4} \cdot$ Li Zheng $^{3} \cdot$ Jinmin Zhao ${ }^{1,4}$
}

Published online: 14 December 2020

(c) Springer-Verlag GmbH Germany, part of Springer Nature 2020

\section{Retraction Note to: Cell Tissue Res}

https://doi.org/10.1007/s00441-014-1797-9

The Editor-in-Chief has retracted this article [1] because there appear to be numerous duplications within Figs. 2, 3, 5 and 6. Due to these duplications, the Editor-in-Chief no longer has confidence in the data and subsequent conclusions drawn from them.

Huayu Wu agrees to this retraction. Li Zheng agrees with the retraction but does not does not agree with the wording. Pan Jin does not agree with the retraction. Guojie $\mathrm{Xu}$ and Jinmin Zhao have not responded to any correspondence from the publisher about this retraction.
The online version of the original article can be found at https:// doi.org/10.1007/s00441-014-1797-9

Li Zheng

zhengli224@163.com

$\triangle$ Jinmin Zhao

zhaojinmin@126.com

1 Department of Orthopaedic Trauma and Hand Surgery, The First Affiliated Hospital of Guangxi Medical University, Nanning 530021, Guangxi, China

2 Department of Cell Biology \& Genetics, School of Premedical Sciences, Guangxi Medical University, Nanning 530021, Guangxi, China

3 The Medical and Scientific Research Center, Guangxi Medical University, Nanning 530021, Guangxi, China

4 Research Center for Regenerative Medicine, Guangxi Medical, University, Nanning 530021, Guangxi, China

\section{Reference}

Jin P, Wu H, Xu G et al (2014) Epigallocatechin-3-gallate (EGCG) as a pro-osteogenic agent to enhance osteogenic differentiation of mesenchymal stem cells from human bone marrow: an in vitro study. Cell Tissue Res 356:381-390. https://doi.org/10.1007/ s00441-014-1797-9

Publisher's Note Springer Nature remains neutral with regard to jurisdictional claims in published maps and institutional affiliations. 